\title{
Spinal anesthesia for Cesarean delivery following pre-existing epidural labour analgesia
}

\author{
Sonia Vaida, MD • Priti Dalal, MD • \\ Berend Mets, PhD
}

Received: 17 August 2009/Accepted: 14 September 2009/Published online: 11 November 2009

(C) Canadian Anesthesiologists' Society 2009

\section{To the Editor,}

We read with interest the retrospective study by Visser et $a{ }^{1}{ }^{1}$ reporting the safe use of spinal anesthesia for Cesarean delivery following a pre-existing labour epidural block. The authors attribute a "poorly justified reputation" to a high or total spinal following a pre-existing epidural block. Spinal administration after a suboptimal labour epidural analgesia remains highly controversial, ${ }^{2}$ and our information is limited to retrospective studies and case reports. $^{3,4}$

A major concern arises when the epidural space has just been bolused and there is now a relative compression of the cerebrospinal fluid. In this situation, the local anesthetic solution injected into the spinal space may be displaced upward resulting in an unpredictably high block. ${ }^{4}$ As the authors admit, a major limitation of the study is the fact that the block heights were not recorded. A statement cannot be made regarding a "high spinal block" without knowing the actual level of block.

Further, the definition used to define a high block is, "patient complaining of impaired breathing". This definition is misleading, as dyspnea during Cesarean delivery is an imprecise indicator of the block height and can also be attributed to blunting of thoracic proprioception or partial block of abdominal and intercostal muscles. ${ }^{5}$

Finally, despite the authors' reporting the safe use of a single-shot spinal following a pre-existing epidural anesthesia (by infusion), a recent epidural bolus prior to spinal administration may result in an unpredictably higher level of anesthesia than intended. Therefore, it remains very

S. Vaida, MD $(\bowtie) \cdot$ P. Dalal, MD · B. Mets, PhD

Penn State Milton S. Hershey Medical Center,

Hershey, PA, USA

e-mail: svaida@hmc.psu.edu important to carefully monitor the patient for symptoms that suggest a rapidly developing high spinal block and to be prepared to intervene should this complication occur.

Competing interests None declared.

\section{References}

1. Visser WA, Dijkstra A, Albayrak M, Gielen MJ, Boersma E, Vonsée HJ. Spinal anesthesia for intrapartum cesarean delivery following epidural labor analgesia: a retrospective cohort study. Can J Anesth 2009; 56: 577-83.

2. Portnoy D, Vadhera RB. Mechanisms and management of an incomplete epidural block for cesarean section. Anesthesiol Clin North Am 2003; 21: 39-57.

3. Mets B, Broccoli E, Brown AR. Is spinal anesthesia after failed epidural anesthesia contraindicated for cesarean section? Anesth Analg 1993; 77: 629-31.

4. Gupta A. Spinal anesthesia after failed epidural anesthesia. Anesth Analg 1996; 82: 214-5.

5. Tsen L. Anesthesia for cesarean section. In: Chestnut DH, Polley LS, Tsen LC, Wong CA, editors. Chestnut's Obstetric Anesthesia: Principles and Practice. 4th ed. Philadelphia: Elsevier Mosby; 2009. p. 552.

\section{Reply}

We thank Vaida et al. for their interest in our study. However, we feel the issues raised in their letter were discussed extensively in our article and the limitations of our study were sufficiently underlined. Certainly, we can only agree that monitoring the patient carefully for signs of high spinal block remains extremely important when undertaking spinal anesthesia following epidural labour analgesia. As noted by Vaida et al., the literature on this issue consists almost entirely of case reports, and most of 
these describe either high block or total spinal block after failed topped-up epidural analgesia. While we do not wish to advocate abandoning conversion of epidural labour analgesia to epidural surgical anesthesia altogether, if there is only the weakest doubt about the proper functioning of the epidural in a woman presenting for Cesarean delivery, we believe it may be better to move to spinal anesthesia at the outset. This will obviate the need for bolus doses of epidural local anesthetic, which would likely increase the risk of high spinal block by way of the mechanism described by Dr Vaida and colleagues, should spinal anesthesia be attempted when epidural anesthesia fails. While taking into consideration the retrospective design and limited statistical power of our study, we believe our data support the efficacy and safety of this technique in the absence of prospective studies. We are pleased that Vaida et al. also make the distinction in the last paragraph of their letter between spinal anesthesia following epidural labour analgesia by infusion only and spinal anesthesia following recent epidural bolus administration.

Competing interests None declared.

W. Anton Visser, MD

Annemieke Dijkstra, MD

Mustafa Albayrak, MD

Henk J. Vonsée, MD, PhD

Amphia Hospital, Breda, The Netherlands

Mathieu J. M. Gielen, MD

University Medical Center Nijmegen, Nijmegen,

The Netherlands

Eric Boersma, MD, $\mathrm{PhD}$

Erasmus Medical Center, Rotterdam, The Netherlands 